\title{
Hepatitis C Virus-Infected Responders and Relapsers to Treatment Show Similar Genetic Profiles of IL28B and ILIO Single Nucleotide Polymorphisms
}

\author{
Suiane Lima de Souza, ${ }^{1}$ Luãnna Liebscher Vidal, ${ }^{1}$ Juliene Ramos, ${ }^{1}$ \\ Cynthia Chester Cardoso, ${ }^{1}$ Henrique Sérgio Moraes Coelho, ${ }^{1}$ \\ Cristiane Alves Villela-Nogueira $\left(\mathbb{D},{ }^{1}\right.$ Renata de Mello Perez, ${ }^{1,2}$ \\ Marcelo Alves Soares $\mathbb{D},,^{1,3}$ and André Felipe Santos $\mathbb{D}^{1}$ \\ ${ }^{1}$ Universidade Federal do Rio de Janeiro, Rio de Janeiro, RJ, Brazil \\ ${ }^{2}$ D'Or Institute for Research and Education (IDOR), Rio de Janeiro, RJ, Brazil \\ ${ }^{3}$ Instituto Nacional do Câncer, Rio de Janeiro, RJ, Brazil \\ Correspondence should be addressed to André Felipe Santos; andre.santos@ufrj.br
}

Received 17 January 2018; Revised 26 March 2018; Accepted 12 April 2018; Published 20 May 2018

Academic Editor: Xiaofeng Fan

\begin{abstract}
Copyright (C) 2018 Suiane Lima de Souza et al. This is an open access article distributed under the Creative Commons Attribution License, which permits unrestricted use, distribution, and reproduction in any medium, provided the original work is properly cited.
\end{abstract}

Genotype 1 of hepatitis $\mathrm{C}$ virus (HCV) is the most prevalent worldwide. Pegylated-interferon and ribavirin therapy is still used in the developing world but has less efficiency in this genotype. Single nucleotide polymorphisms (SNPs) rs12979860 and rs8099917 (IL28B) and rs1800896, rs1800871, and rs1800872 (IL10) are related to treatment outcome, but previous studies clustered nonresponse and relapse patients. The aim of this study is to analyze the frequency of those SNPs in HCV genotype 1 for response, nonresponse, or relapse. Patients were classified according to treatment outcome. Genomic DNA was extracted by blood samples and SNPs were defined by PCR and sequencing. Data analysis was performed with R project. The frequency of rs12979860 CC was similar among responders (0.48) and relapsers (0.46) and lower among nonresponders (0.18). The same trend was observed for rs8099917 TT. rs12979860 CC showed a protective effect for relapsers compared to nonresponders $(\mathrm{OR}=0.25)$ as it occurs with responders $(\mathrm{OR}=0.17)$. Haplotypes $12979860 / \mathrm{C}$ rs8099917/T were associated with protection against the nonresponder phenotype compared to responders $(\mathrm{OR}=0.27)$ or relapsers $(\mathrm{OR}=0.37)$. Frequency of rs12979860 and rs8099917 is different between relapsers and nonresponders, but similar between relapsers and responders.

\section{Introduction}

Currently 130-150 million people, approximately $2 \%$ of the world population, are infected with the hepatitis $\mathrm{C}$ virus (HCV) worldwide [1]. HCV has seven acknowledged genotypes (1-7), but genotype 1 (genl) is the most prevalent, being responsible for $46 \%$ of cases [2]. Despite such high prevalence, only $50 \%$ of HCV genl-infected patients achieve sustained virological response (SVR) with pegylatedinterferon (pegIFN) and ribavirin (RBV) dual therapy, while SVR occurs in $80 \%$ of patients with other genotypes [3]. Although this therapeutic regimen has been overcome by the development of direct acting antivirals (DAA), it is still widely used in the developing world.

The outcomes related to failure to pegIFN/RBV treatment are classified into nonresponse, when the HCV viral load does not decrease or decreases less than 2 log of the baseline HCV-RNA load, or relapse, when the viral load becomes undetectable at the end of treatment, but it is again detectable 24 weeks after the end of treatment [4]. Independent GWAS studies showed two single nucleotide polymorphisms (SNPs) close to the IL28B gene, rs12979860 C/T and rs8099917 T/G, which are related to the outcome of this treatment $[5,6]$. IL10 SNPs rs1800896 A/G, rs1800871 C/T, and rs1800872 A/C, 
located, respectively, at positions $-1082,-819$, and -592 of the promoter region of that gene, are also related to pegIFN/RBV treatment outcome, but there is a controversial relationship between those SNPs and HCV. Some studies showed an association with treatment $[7,8]$, but others have shown no difference between failure patients and patients who achieve SVR $[9,10]$.

The previously mentioned studies that suggested the association of IL28B and IL10 SNPs with SVR after pegIFN and RBV therapy clustered nonresponder and relapser patients in treatment failure. A multicenter study suggested different genetic frequencies of rs12979860 and rs8099917 between these two groups of patients [11] specifically for HCV gen2 and 3 , and the analysis did not compare individually the nonresponders and the relapsers with the RVS patients. A detailed analysis of those types of patients in an individual manner, particularly in the context of HCV gen1 infection, is still lacking, what has prompted us to study the frequency of those SNPs in that HCV genotype.

\section{Materials and Methods}

2.1. Study Population. Two hundred and fifty-nine HCVinfected patients with genotype 1 , with absence of coinfection by HIV or HBV and without chronic kidney disease, were recruited from Clementino Fraga Filho University Hospital (HUCCF) of Federal University of Rio de Janeiro, Brazil, between 2012 and 2015. All patients were at least 18 years old. All samples were previously genotyped by real time PCR in the hospital and had HCV viral strains belonging to genotype 1. Patients with previous treatment failure with pegIFN/RBV were classified according to the outcome into nonresponders or relapsers, whereas those with SVR after the treatment were classified as responders. All patients recruited received pegINF/RBV for 48 weeks, and there were no cases of patients who discontinued the therapy. Medical records provided by the hospital were consulted to access data of treatment response and viral genotype and subtype. The group of patients who successfully responded to the anti$\mathrm{HCV}$ dual therapy was used as control to this study and was compared to the other groups for all five SNPs comprising the $I L 28 B$ and the $I L 10$ genes. Considering a minor allele frequency (MAF) of 0.2 and the characteristics observed in comparisons between relapsers and responders $(N=61$, fraction of cases $=0.57$ and outcome prevalence $=0.28)$, which were the most stringent conditions observed in our study, the minimal OR values to reach a power of $80 \%$ were between 3.5 and 4 .

In addition, a group of 112 healthy individuals was also included in the study as a population control, to determine allele frequencies and possible deviations from Hardy-Weinberg Equilibrium. All individuals had absence of coinfection by HIV, HBV, or HCV and were at least 18 years old. The present study has been approved by the Ethics Committee in Research of HUCCF with the number (CAAE) 22786113.8.0000.5257.

2.2. DNA Extraction, PCR, and Sequencing. Genomic DNA extraction were performed from blood samples with the
PureLink $^{\circledR}$ Genomic DNA Mini Kit (Invitrogen, Carlsbad, USA) following the manufacturer's protocol. DNA quantification was carried out in a Nanovue Plus spectrophotometer (GE Healthcare, Little Chalfont). PCRs for the IL28B rs12979860 and rs8099917 SNP analysis fragments were performed as described by Moreira et al. [12] and Sharafi et al. [13], respectively. The PCR for the IL10 rs1800896, rs1800871, and rs1800872 SNPs was performed in a single DNA fragment spanning all three SNPs. The PCR reaction used $1 x$ PCR $R x$ buffer, $2 \mathrm{mM} \mathrm{MgCl}_{2}, 0.25 \mathrm{mM}$ dNTP, $0.5 \mathrm{pmol}$ of each primer $5^{\prime}$-CTGGCTCCCCTTACCTTCTAC-3' (forward) and $5^{\prime}$ CCTAGGTCACAGTGACGTGG-3' (reverse), $1 \mathrm{U}$ Taq polymerase (Invitrogen), and 50-500 ng of genomic DNA in a total volume of $50 \mu \mathrm{L}$. The reaction cycling was $95^{\circ} \mathrm{C}$ for $3 \mathrm{~min}$, followed by 35 cycles with $95^{\circ} \mathrm{C}$ for $45 \mathrm{sec}, 57^{\circ} \mathrm{C}$ for $40 \mathrm{sec}$, and $72^{\circ} \mathrm{C}$ for $1 \mathrm{~min}$, and a final extension step of $72^{\circ} \mathrm{C}$ for $7 \mathrm{~min}$.

PCR amplification of DNA fragments was confirmed by $1.5 \%$ agarose gel electrophoresis and samples were then purified using the HiYield Gel/PCR DNA Mini kit (Real Genomics, Miami, USA), following the manufacturer's instructions. DNA sequencing was carried out using the same primers of the PCRs and the Big Dye Terminator Cycle Sequencing kit v3.1 (Life Technologies), according to the manufacturer's instructions, in an Applied Biosystems 3130 Genetic Analyzer platform (Life Technologies). Sequences were analyzed to visually identify the SNPs with the BioEdit program.

2.3. Data Analysis. Statistical analyses were performed with $\mathrm{R}$ project v. 3.3.1 [14]. Frequencies of each genotype and allele were determined by direct counting. Deviations from HardyWeinberg Equilibrium were assessed using data from healthy controls using a $\chi^{2}$ test. Frequencies of each SNP were compared between the three different patient groups (responders, nonresponders, and relapsers) using unconditional logistic regression models. Allele frequencies were compared among responders and nonresponders, responders and relapsers, and relapsers and nonresponders for each SNP using $\chi^{2}$ test.

A codominant model was considered primarily and, afterwards, analysis under dominant and recessive models was also performed when appropriate. Multivariate models were applied to combine the effect of IL28B SNPs. Pairwise linkage disequilibrium patterns were determined using $r^{2}$ statistics. Haplotype frequencies were estimated by maximum likelihood and compared between the groups using logistic regression models. $p$ values below 0.05 were considered significant.

\section{Results}

Overall, 125 patients were included in this study, 64 of which (51\%) were nonresponders, 35 (28\%) were relapsers, and 26 (21\%) were responders. Of the participants, 56 (45\%) were infected with HCV subtype la, while 56 (45\%) were infected with HCV subtype 1 b and only 1 (1\%) carried HCV subtype 1c. Besides that, 12 (9\%) did not have the subtype determined in their medical records. In addition, 58 (46\%) of the patients were women and the median age was 56 years (Table 1). 

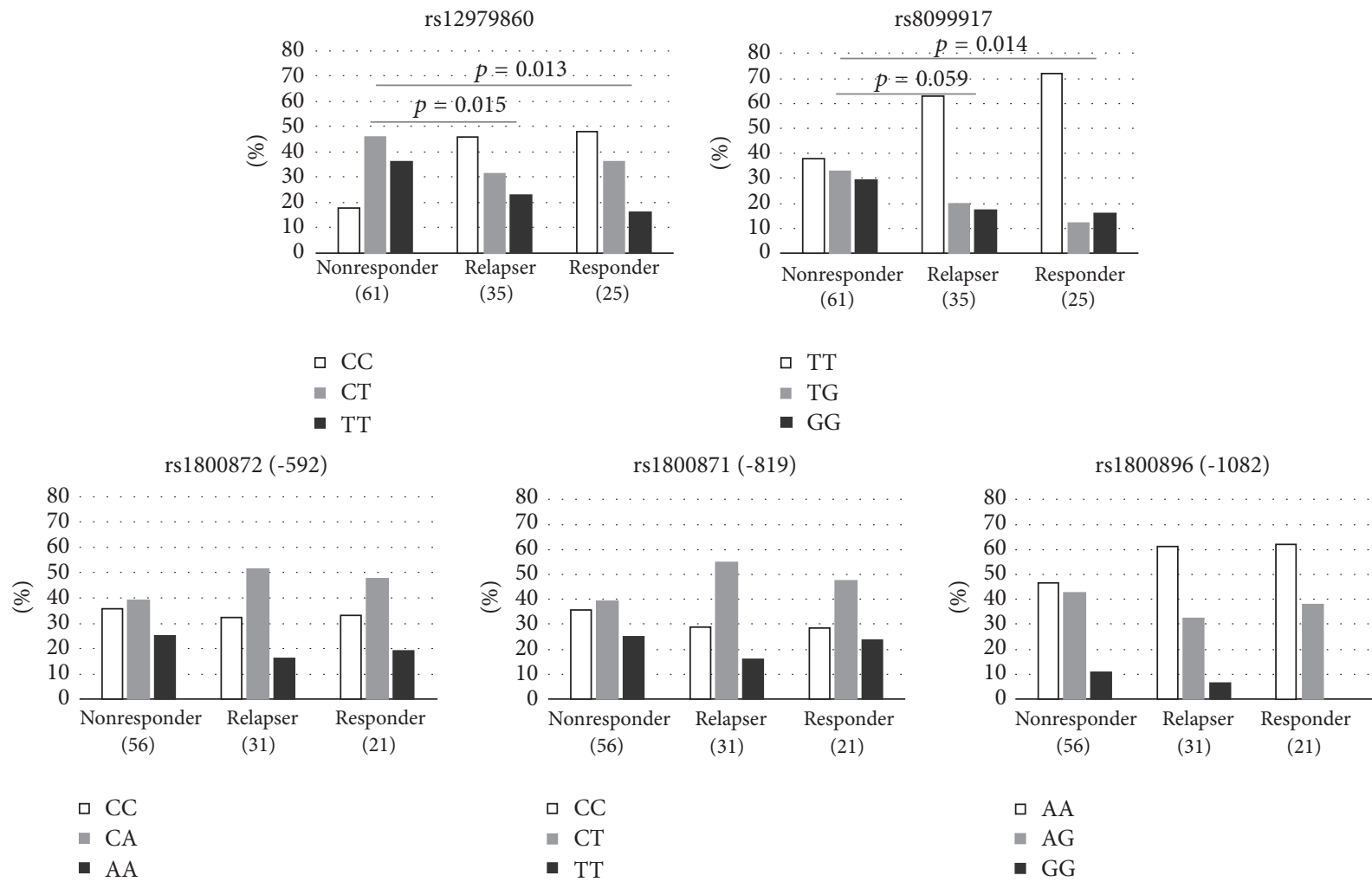

FIGURE 1: IL28B and IL10 SNP frequency comparisons among nonresponders, relapsers, and responders. Frequencies were compared using chi-square test with 2 degrees of freedom. Significant values were found only for SNPs rs12979860 and rs8099917, both from the IL28B gene.

TABLE 1: Demographic and clinical characteristics of patients infected with HCV genotype 1 .

\begin{tabular}{lc}
\hline Variable & $\begin{array}{c}\text { Total } \\
\text { population } \\
(n=125)\end{array}$ \\
\hline Gender & $58(46 \%)$ \\
Female (\%) & $67(54 \%)$ \\
Male (\%) & \\
Age & $54-56$ \\
Mean-median & \\
Viral load log10* & $5.82-5.9$ \\
Mean-median & \\
AST/TGO & $76.9(66)$ \\
$\quad$ Mean-median & \\
Treatment outcome & $26(21 \%)$ \\
Responders & $35(28 \%)$ \\
Relapsers & $64(51 \%)$ \\
Nonresponders & \\
Genotype 1 diversity & \\
Subtype la (\%) & $56(45 \%)$ \\
Subtype 1b (\%) & $56(45 \%)$ \\
Subtype 1c (\%) & $1(1 \%)$ \\
\hline
\end{tabular}

${ }^{*}$ Viral load before treatment.
Different treatment outcomes did not show variations among age, sex, and other characteristics.

In the population control, formed by samples of healthy individuals, all frequencies of the five SNPs did not show deviations from Hardy-Weinberg Equilibrium: frequencies for $\operatorname{rs} 12979860$ were $0.52 \mathrm{CC}, 0.34 \mathrm{CT}$, and $0.14 \mathrm{TT}(p=$ $0.059)$; 0.71 TT, $0.24 \mathrm{TG}$, and 0.05 for $\mathrm{rs} 8099917(p=0.179)$; 0.37 CC, $0.50 \mathrm{CA}$, and $0.13 \mathrm{AA}$ for $\mathrm{rs} 1800872(p=0.682) ; 0.39$ CC, 0.47 CT, and 0.14 TT for rs1800871 $(p=1)$; and 0.46 AA, $0.44 \mathrm{AG}$, and $0.10 \mathrm{GG}$ for $\operatorname{rs1800896}(p=1)$.

The frequency of the favorable genotype CC for the IL28B SNP rs12979860 was similar among responders and relapsers ( 0.48 and 0.46 , respectively). As expected, the frequency of that genotype was significantly lower among nonresponders $(0.18 ; p=0.013$ and 0.015 for comparisons with responders and relapsers, respectively) (Figure 1). The same trend was observed for the IL28B SNP rs8099917, with similar frequencies of genotype TT among responders and relapsers ( 0.72 and 0.63 , respectively). Both patient groups were also different from nonresponders $(p=0.014$ and 0.059 , respectively), who showed a frequency of 0.38 for that genotype. No associations were observed for IL10 SNPs rs1800896, rs1800871, and rs1800872 in the comparisons among responders, relapsers, and nonresponders frequencies.

Comparisons between responders and nonresponders confirmed the protective effect of rs12979860 CC $(\mathrm{OR}=0.17$; ${ }_{95 \%}$ CI: $\left.0.04-0.64 ; p=0.009\right)$ and of $\operatorname{rs} 8099917 \mathrm{TT}(\mathrm{OR}=0.28$; 
TABLE 2: Association between IL28B and IL10 SNPs and responders and nonresponders.

\begin{tabular}{|c|c|c|c|c|}
\hline Genotype/haplotype & Responders & Nonresponders & OR $(95 \%$ CI $)$ & OR $(95 \% \mathrm{CI})^{*}$ \\
\hline \multicolumn{5}{|l|}{ rs12979860 } \\
\hline TT & $4(0.16)$ & $22(0.36)$ & Reference & Reference \\
\hline $\mathrm{CT}$ & $9(0.36)$ & $28(0.46)$ & $0.57(0.15-2.08)(p=0.392)$ & $0.46(0.12-1.80)(p=0.268)$ \\
\hline $\mathrm{CC}$ & $12(0.48)$ & $11(0.18)$ & $0.17(0.04-0.64)(\mathbf{p}=\mathbf{0 . 0 0 9})$ & $0.18(0.04-0.76)(\mathbf{p}=\mathbf{0 . 0 1 9})$ \\
\hline $\mathrm{CC}$ versus CT/TT & & & $0.24(0.09-0.66)(\mathbf{p}=\mathbf{0 . 0 0 6})$ & $0.31(0.11-0.90)(\mathbf{p}=\mathbf{0 . 0 3})$ \\
\hline \multicolumn{5}{|l|}{ rs8099917 } \\
\hline GG & $4(0.16)$ & $18(0.30)$ & Reference & Reference \\
\hline GT & $3(0.12)$ & $20(0.33)$ & $1.48(0.29-7.54)(p=0.636)$ & $2.18(0.40-11.93)(p=0.369)$ \\
\hline TT & $18(0.72)$ & $23(0.38)$ & $0.28(0.08-0.99)(\mathbf{p}=\mathbf{0 . 0 4 7})$ & $0.42(0.11-1.59)(p=0.203)$ \\
\hline TT versus GT/GG & & & $0.23(0.08-0.64)(\mathbf{p}=\mathbf{0 . 0 0 5})$ & $0.29(0.10-0.84)(\mathbf{p}=\mathbf{0 . 0 2})$ \\
\hline \multicolumn{5}{|l|}{ rs1800872 (-592) } \\
\hline CC & $7(0.33)$ & $20(0.36)$ & Reference & \\
\hline CA & $10(0.48)$ & $22(0.39)$ & $0.77(0.25-2.41)(p=0.65)$ & \\
\hline AA & $4(0.19)$ & $14(0.25)$ & $1.22(0.30-4.99)(p=0.77)$ & \\
\hline CA/AA versus CC & & & $0.9(0.31-2.60)(p=0.84)$ & \\
\hline \multicolumn{5}{|l|}{ rs1800871 (-819) } \\
\hline $\mathrm{CC}$ & $6(0.29)$ & $20(0.36)$ & Reference & \\
\hline $\mathrm{CT}$ & $10(0.48)$ & $22(0.39)$ & $0.66(0.20-2.14)(p=0.49)$ & \\
\hline TT & $5(0.24)$ & $14(0.25)$ & $0.84(0.21-3.30)(p=0.80)$ & \\
\hline CT/TT versus CC & & & $0.72(0.24-2.14)(p=0.56)$ & \\
\hline \multicolumn{5}{|l|}{ rs1800896 (-1082) } \\
\hline AA & $13(0.62)$ & $26(0.46)$ & Reference & \\
\hline GA & $8(0.38)$ & $24(0.43)$ & $0.67(0.24-1.89)(p=0.445)$ & \\
\hline GG & 0 & $6(0.11)$ & not done & \\
\hline GA/GG versus AA & & & $1.88(0.67-5.22)(p=0.22)$ & \\
\hline \multicolumn{5}{|l|}{ rs12979860/rs8099917 } \\
\hline $\mathrm{T} / \mathrm{G}$ & 0.13 & 0.31 & Reference & \\
\hline $\mathrm{C} / \mathrm{G}$ & 0.09 & 0.15 & $0.69(0.16-3.03)(p=0.623)$ & \\
\hline $\mathrm{C} / \mathrm{T}$ & 0.57 & 0.26 & $0.27(0.11-0.68)(\mathbf{p}=\mathbf{0 . 0 0 7})$ & \\
\hline $\mathrm{T} / \mathrm{T}$ & 0.21 & 0.28 & $0.68(0.24-1.88)(p=0.455)$ & \\
\hline
\end{tabular}

OR: odds ratio; CI: confidence interval. * Multivariate models including rs12979860 and rs8099917. Comparisons between crude (rs12979860) and multivariate model including rs12979860 and rs8099917 were statistically significant in codominant $(p=0.04)$ and recessive models $(p=0.02)$. Haplotype frequencies were estimated by maximum likelihood.

${ }_{95 \%}$ CI: $0.08-0.99 ; p=0.047$ ) in our population (Table 2). Results were similar when analysis was performed under a recessive model $(\mathrm{OR}=0.24 ; p=0.006$ for $\mathrm{rs} 12979860 \mathrm{CC}$ versus CT/TT and OR $=0.23 ; p=0.005$ for rs8099917 TT versus GT/GG). Surprisingly, rs12979860 CC also showed a protective effect for relapsers compared to nonresponders in both codominant $\left(\mathrm{OR}=0.25,{ }_{95 \%} \mathrm{CI}: 0.08-0.76 ; p=0.015\right)$ and recessive $(0.26 ; 0.10-0.66 ; p=0.005)$ models, as it occurs with responders (Table 3 ). No association was observed when frequency of IL28B SNPs was compared between relapsers and nonresponders (Table 3).

Haplotype analyses corroborated our findings, since the haplotype carrying allele C at rs12979860 and T at rs8099917 was associated with protection against the nonresponder phenotype when compared to responders $\left(\mathrm{OR}=0.27 ;{ }_{95 \%} \mathrm{CI}\right.$ : $0.11-0.68 ; p=0.007)$ or to relapsers $\left(\mathrm{OR}=0.37 ;{ }_{95 \%} \mathrm{CI}\right.$ : 0.18-0.77; $p=0.009)$. Comparisons between responders and relapsers showed no difference between those groups, reinforcing that they are genetically similar (Table 4).

Multivariate analyses were also performed to assess a possible confounding effect between the IL28B SNPs in both codominant and recessive models. In comparisons between responders and nonresponders, the $\mathrm{OR}$ values obtained for rs12979860 CC remained similar after adjustment for rs8099917 in the codominant model (OR $=0.17 ;{ }_{95 \%} \mathrm{CI}$ : 0.04-0.64 and ${ }_{\text {adj }} \mathrm{OR}=0.18 ;{ }_{95 \%} \mathrm{CI}$ : 0.04-0.76, respectively). When the recessive model was considered, the OR values were increased, suggesting that inclusion of rs8099917 has adjusted the effect of the rs12979860 CC genotype (OR = 0.24; ${ }_{95 \%} \mathrm{CI}: 0.09-0.66$ and ${ }_{\text {adj }} \mathrm{OR}=0.31 ;{ }_{95 \%} \mathrm{CI}: 0.11-0.90$, respectively). Comparisons between crude and multivariate models were statistically significant in both models $(p=0.04$ and 0.02 for codominant and recessive models, respectively), suggesting that inclusion of rs8099917 reduced the model 
TABLE 3: Association between IL28B and IL10 SNPs and relapsers and nonresponders.

\begin{tabular}{|c|c|c|c|}
\hline Genotype/haplotype & Relapsers & Nonresponders & OR $(95 \% \mathrm{CI})$ \\
\hline \multicolumn{4}{|l|}{ rs12979860 } \\
\hline TT & $8(0.23)$ & $22(0.36)$ & Reference \\
\hline $\mathrm{CT}$ & $11(0.31)$ & $28(0.46)$ & $0.93(0.32-2.69)(p=0.887)$ \\
\hline $\mathrm{CC}$ & $16(0.46)$ & $11(0.18)$ & $0.25(0.08-0.76)(\mathbf{p}=\mathbf{0 . 0 1 5})$ \\
\hline $\mathrm{CC}$ versus CT/TT & & & $0.26(0.10-0.66)(\mathbf{p}=\mathbf{0 . 0 0 5})$ \\
\hline \multicolumn{4}{|l|}{ rs8099917 } \\
\hline GG & $6(0.17)$ & $18(0.30)$ & Reference \\
\hline GT & $7(0.20)$ & $20(0.33)$ & $0.95(0.27-3.37)(p=0.940)$ \\
\hline TT & $22(0.63)$ & $23(0.38)$ & $0.35(0.12-1.04)(\mathbf{p}=\mathbf{0 . 0 5 9})$ \\
\hline TT versus GT/GG & & & $0.36(0.15-0.84)(\mathbf{p}=\mathbf{0 . 0 1 9})$ \\
\hline \multicolumn{4}{|l|}{ rs1800872 (-592) } \\
\hline $\mathrm{CC}$ & $10(0.32)$ & $20(0.36)$ & Reference \\
\hline $\mathrm{CA}$ & $16(0.52)$ & $22(0.39)$ & $0.69(0.25-1.86)(p=0.46)$ \\
\hline $\mathrm{AA}$ & $5(0.16)$ & $14(0.25)$ & $1.4(0.39-4.99)(p=0.60)$ \\
\hline $\mathrm{CA} / \mathrm{AA}$ versus $\mathrm{CC}$ & & & $0.86(0.34-2.17)(p=0.74)$ \\
\hline \multicolumn{4}{|l|}{ rs1800871 (-819) } \\
\hline $\mathrm{CC}$ & $9(0.29)$ & $20(0.36)$ & Reference \\
\hline CT & $17(0.55)$ & $22(0.39)$ & $0.58(0.21-1.59)(p=0.29)$ \\
\hline TT & $5(0.16)$ & $14(0.25)$ & $1.26(0.35-4.57)(p=0.72)$ \\
\hline $\mathrm{CT} / \mathrm{TT}$ versus CC & & & $0.74(0.28-1.90)(p=0.53)$ \\
\hline \multicolumn{4}{|l|}{ rs1800896 (-1082) } \\
\hline AA & $19(0.61)$ & $26(0.46)$ & Reference \\
\hline GA & $10(0.32)$ & $24(0.43)$ & $1.75(0.68-4.51)(p=0.24)$ \\
\hline GG & $2(0.06)$ & $6(0.11)$ & $2.19(0.39-12.07)(p=0.37)$ \\
\hline GA/GG & & & $1.83(0.74-4.46)(p=0.19)$ \\
\hline \multicolumn{4}{|l|}{ rs12979860/rs8099917 } \\
\hline $\mathrm{T} / \mathrm{G}$ & 0.18 & 0.31 & Reference \\
\hline $\mathrm{C} / \mathrm{G}$ & 0.10 & 0.15 & $0.84(0.28-2.54)(p=0.752)$ \\
\hline $\mathrm{C} / \mathrm{T}$ & 0.52 & 0.26 & $0.37(0.18-0.77)(\mathbf{p}=\mathbf{0 . 0 0 9})$ \\
\hline $\mathrm{T} / \mathrm{T}$ & 0.21 & 0.28 & $0.84(0.36-1.93)(p=0.675)$ \\
\hline
\end{tabular}

Haplotype frequencies were estimated by maximum likelihood. OR: odds ratio; CI: confidence interval.

variance. However, association of both SNPs remained statistically significant in the multivariate model, suggesting an independent effect in this outcome (Table 2). Indeed, results of linkage disequilibrium analysis showed a low $r^{2}(0.11)$ between IL28B SNPs in our population.

Again, no associations were observed for IL10 promoter SNPs rs1800896, rs1800871, and rs1800872 in all analyses performed.

\section{Discussion}

This study describes that only IL28B SNPs showed significant differences in frequency between responders and nonresponders, as well as a protective effect of genotypes rs12979860 CC and rs8099917 TT against a nonresponder phenotype. The three IL10 SNPs did not show differences between the compared groups. The latter SNPs are controversial in the literature, with some studies population showing an association with pegIFN/RBV therapy and others showing no effect $[9,15]$. In this study, we did not find any significant association of IL10 SNPs with response to therapy in a population of Rio de Janeiro, neither in frequency nor in OR. We have also compared all SNPs between nonresponders and relapsers in order to evaluate differences between those two types of patients. Once again, the IL10 SNPs did not show any significant differences between the two groups, but IL28B SNPs rs12979860 and rs8099917 showed differences in frequency and also in the protective effect of genotypes CC and TT against being a nonresponder, just like the one seen between responders and nonresponders. Given that the union of both nonresponders and relapsers groups of therapy failure is common in the literature, our study highlights that they have significant differences in the frequency of IL28B SNPs rs12979860 and rs8099917, two of the most important SNPs associated with response to HCV therapy [11]. While nonresponders and responders had differences in the genotypic frequencies of rs12979860 and rs8099917, this did not occur when comparing relapsers and responders. Therefore, clustering nonresponders and relapsers can lead to an incorrect association or a lack of association between those 
TABLE 4: Association between IL28B and IL10 SNPs and responders and relapsers.

\begin{tabular}{|c|c|c|c|}
\hline Genotype/haplotype & Responders & Relapsers & OR $(95 \% \mathrm{CI})$ \\
\hline \multicolumn{4}{|l|}{ rs12979860 } \\
\hline TT & $4(0.16)$ & $8(0.23)$ & Reference \\
\hline CT & $9(0.36)$ & $11(0.31)$ & $0.61(0.13-2.71)(p=0.517)$ \\
\hline $\mathrm{CC}$ & $12(0.48)$ & $16(0.46)$ & $0.67(0.16-2.74)(p=0.574)$ \\
\hline $\mathrm{CC}$ versus $\mathrm{CT} / \mathrm{TT}$ & & & $0.91(0.32-2.55)(p=0.86)$ \\
\hline \multicolumn{4}{|l|}{ rs8099917 } \\
\hline GG & $4(0.16)$ & $6(0.17)$ & Reference \\
\hline GT & $3(0.12)$ & $7(0.20)$ & $1.56(0.24-9.91)(p=0.640)$ \\
\hline TT & $18(0.72)$ & $22(0.63)$ & $0.81(0.20-3.34)(p=0.776)$ \\
\hline TT versus GT/GG & & & $0.66(0.22-2.00)(p=0.46)$ \\
\hline \multicolumn{4}{|l|}{ rs1800872 (-592) } \\
\hline $\mathrm{CC}$ & $7(0.33)$ & $10(0.32)$ & Reference \\
\hline $\mathrm{CA}$ & $10(0.48)$ & $16(0.52)$ & $1.12(0.32-3.90)(p=0.86)$ \\
\hline AA & $4(0.19)$ & $5(0.16)$ & $0.87(0.17-4.47)(p=0.87)$ \\
\hline CA/AA versus CC & & & $1.05(0.32-3.41)(p=0.93)$ \\
\hline \multicolumn{4}{|l|}{ rs1800871 (-819) } \\
\hline $\mathrm{CC}$ & $6(0.29)$ & $9(0.29)$ & Reference \\
\hline CT & $10(0.48)$ & $17(0.55)$ & $1.13(0.31-4.13)(p=0.85)$ \\
\hline TT & $5(0.24)$ & $5(0.16)$ & $0.67(0.13-3.34)(p=0.62)$ \\
\hline $\mathrm{CT} / \mathrm{TT}$ versus CC & & & $0.98(0.29-3.32)(p=0.97)$ \\
\hline \multicolumn{4}{|l|}{ rs1800896 (-1082) } \\
\hline AA & $13(0.62)$ & $19(0.61)$ & Reference \\
\hline GA & $8(0.38)$ & $10(0.32)$ & $0.85(0.26-2.74)(p=0.79)$ \\
\hline GG & 0 & $2(0.06)$ & Not done \\
\hline GA/GG versus AA & & & $1.02(0.32-3.20)(p=0.96)$ \\
\hline \multicolumn{4}{|l|}{ rs12979860/rs8099917 } \\
\hline $\mathrm{T} / \mathrm{G}$ & 0.13 & 0.18 & Reference \\
\hline $\mathrm{C} / \mathrm{G}$ & 0.09 & 0.10 & $0.83(0.18-3.88)(p=0.810)$ \\
\hline $\mathrm{C} / \mathrm{T}$ & 0.57 & 0.52 & $0.76(0.30-1.94)(p=0.567)$ \\
\hline $\mathrm{T} / \mathrm{T}$ & 0.21 & 0.21 & $0.82(0.27-2.54)(p=0.736)$ \\
\hline
\end{tabular}

Haplotype frequencies were estimated by maximum likelihood. OR: odds ratio; CI: confidence interval.

SNPs and response to treatment. Responders and relapsers are similar on the distribution of the IL28B SNP genotypes. In fact, both groups have a good initial response to therapy since in both cases the HCV viral load gets undetectable, but at the end of the therapy responders remain undetectable while $\mathrm{HCV}$ rebounds in relapsers.

The IL10 promoter SNPs rs1800872 (-592), rs1800871 ($819)$, and rs1800896 (-1082) did not show any association with any specific group of patients in this study, corroborating the controversial nature of the potential association of those SNPs with anti-HCV therapy, and in agreement with other reports that failed to observe significant associations $[16,17]$.

Until 2013, the mechanism of SNPs in the spontaneous cure of HCV was unclear. This fact changed with the discovery of the rs368234815 SNP very close to rs12979860, in the first exon of the new characterization human gene named IL-28C. This is a functional SNP, which the variation $\Delta \mathrm{G}$ produces the interferon $\lambda 4$ and the variation TT causes a change in the reading frame and culminates in a premature stop codon [18]. rs368234815 is now considered the true functional variant related to the treatment outcome: the production of interferon $\lambda 4$ is unfavorable to hepatitis $C$ virus clearance and it is associated with treatment failure [19]. This SNP is in strong linkage disequilibrium with rs12979860, with the allele TT equivalent to allele $\mathrm{C}$ and allele $\Delta \mathrm{G}$ equivalent to allele $\mathrm{T}$, respectively [18].

This study has a limitation that may be considered. pegIFN/RBV HCV treatment is no more the standard of care in HCV therapy after the arrival of DAA therapy in which the role of these polymorphisms is not as strong as in dual therapy. However, many underdeveloped countries still use pegIFN/RBV for treating $\mathrm{HCV}$ infection and thus these results might still have an impact on treatment outcome.

\section{Conclusions}

The frequency of IL28B SNPs rs12979860 and rs8099917 is different between relapsers and nonresponders, showing that those groups need to be analyzed separately in treatment efficacy comparisons. On the other hand, relapsers and 
responders are similar with respect to those IL28B SNP frequencies. In this study, the rs12979860 CC and rs8099917 TT genotypes, as well as the C/T haplotype, were associated with treatment success comparing nonresponse and response to the pegIFN/RBV therapy.

\section{Data Availability}

The data used to support the findings of this study are available from the corresponding author upon request.

\section{Conflicts of Interest}

The authors declare that there are no conflicts of interest regarding the publication of this article.

\section{Acknowledgments}

This study was supported by a Brazilian Ministry of Health and United Nations Office on Drugs and Crime (UNODC) cooperative agreement (no. 114/2013 to Marcelo Alves Soares), by the Brazilian Research Council (CNPq; no. 305085/2013-1 to André Felipe Santos), and by Rio de Janeiro State Science Foundations-FAPERJ (E-26/112.647/2012 to Marcelo Alves Soares and E-26/201.465/2014 to André Felipe Santos). Suiane Lima de Souza has been sponsored by an M.S. scholarship from CNPq by the Graduate Program in Genetics at the Universidade Federal do Rio de Janeiro, Brazil.

\section{References}

[1] WHO, Bulletin of the World Health Organization - Fact sheet No. 164, World Health Organization, 2016.

[2] J. P. Messina, I. Humphreys, A. Flaxman et al., "Global distribution and prevalence of hepatitis C virus genotypes," Hepatology, vol. 61, no. 1, pp. 77-87, 2015.

[3] M. P. Manns, J. G. McHutchison, S. C. Gordon et al., "Peginterferon alfa-2b plus ribavirin compared with interferon alfa$2 \mathrm{~b}$ plus ribavirin for initial treatment of chronic hepatitis C: a randomised trial," The Lancet, vol. 358, no. 9286, pp. 958-965, 2001.

[4] B. N. Fields, D. M. Knipe, and P. M. Howley, Fields Virology, vol. 2, 6th edition, 2013.

[5] D. Ge, J. Fellay, A. J. Thompson et al., "Genetic variation in IL28B predicts hepatitis C treatment-induced viral clearance," Nature, vol. 461, no. 7262, pp. 399-401, 2009.

[6] V. Suppiah, M. Moldovan, G. Ahlenstiel et al., "IL28B is associated with response to chronic hepatitis $\mathrm{C}$ interferon- $\alpha$ and ribavirin therapy," Nature Genetics, vol. 41, no. 10, pp. 1100-1104, 2009.

[7] M. S. Afzal, S. Tahir, A. Salman et al., "Analysis of interleukin-10 gene polymorphisms and hepatitis C susceptibility in Pakistan," The Journal of Infection in Developing Countries, vol. 5, no. 6, pp. 473-479, 2011.

[8] C. J. Edwards-Smith, J. R. Jonsson, D. M. Purdie, A. Bansal, C. Shorthouse, and E. E. Powell, "Interleukin-10 promoter polymorphism predicts initial response of chronic hepatitis C to interferon alfa," Hepatology, vol. 30, no. 2, pp. 526-530, 1999.

[9] G. Dogra, A. Chakravarti, P. Kar, and Y. K. Chawla, "Polymorphism of tumor necrosis factor- $\alpha$ and interleukin-10 gene promoter region in chronic hepatitis $\mathrm{C}$ virus patients and their effect on pegylated interferon- $\alpha$ therapy response," Human Immunology, vol. 72, no. 10, pp. 935-939, 2011.

[10] A. M. TarragÔ, A. G. da Costa, J. P. D. Pimentel et al., "Combined impact of hepatitis $C$ virus genotype 1 and interleukin6 and tumor necrosis factor- $\alpha$ polymorphisms on serum levels of pro-inflammatory cytokines in Brazilian HCV-infected patients," Human Immunology, vol. 75, no. 11, pp. 1075-1083, 2014.

[11] M. Eslam, R. Leung, M. Romero-Gomez et al., "IFNL3 polymorphisms predict response to therapy in chronic hepatitis C genotype 2/3 infection," Journal of Hepatology, vol. 61, no. 2, pp. 235-241, 2014.

[12] S. Moreira, R. F. L. Garcia, A. Gutberlet et al., "A straightforward genotyping of the relevant IL28B SNPs for the prediction of hepatitis C treatment outcome," Journal of Virological Methods, vol. 184, no. 1-2, pp. 93-97, 2012.

[13] H. Sharafi, A. Pouryasin, S. M. Alavian et al., "Distribution of IL28B genotypes in Iranian patients with chronic hepatitis C and healthy individuals," Hepatitis Monthly, vol. 12, no. 12, 2012.

[14] R. Core Team, $R$ : A language and environment for statistical computing. $R$ Foundation for Statistical Computing, Vienna, Austria, 2015.

[15] T. Umemura, S. Joshita, S. Yoneda et al., "Serum interleukin (IL)-10 and IL-12 levels and IL28B gene polymorphisms: Pretreatment prediction of treatment failure in chronic hepatitis C," Antiviral Therapy, vol. 16, no. 7, pp. 1073-1080, 2011.

[16] W. M. Abdelraheem, N. A. Hassuna, S. M. Abuloyoun, H. M. Abdel Ghany, H. A. Rizk, and S. F. Abdelwahab, "Interleukin10.rs1800896 and Interleukin-18.rs1946518 gene polymorphisms could not predict the outcome of hepatitis $\mathrm{C}$ virus infection in Egyptian patients treated with pegylated interferon plus ribavirin," Archives of Virology, vol. 161, no. 9, pp. 2473-2480, 2016.

[17] P. K. Constantini, M. Wawrzynowicz-Syczewska, M. Clare et al., "Interleukin-1, interleukin-10 and tumour necrosis factoralpha gene polymorphisms in hepatitis $\mathrm{C}$ virus infection: An investigation of the relationships with spontaneous viral clearance and response to alpha-interferon therapy," Journal of Liver, vol. 22, no. 5, pp. 404-412, 2002.

[18] L. Prokunina-Olsson, B. Muchmore, W. Tang et al., "A variant upstream of IFNL3 (IL28B) creating a new interferon gene IFNL4 is associated with impaired clearance of hepatitis C virus," Nature Genetics, vol. 45, no. 2, pp. 164-171, 2013.

[19] T. R. O’Brien, L. Prokunina-Olsson, and R. P. Donnelly, "IFN$\lambda 4$ : the paradoxical new member of the interferon lambda family," Journal of Interferon \& Cytokine Research, vol. 34, no. 11, pp. 829-838, 2014. 


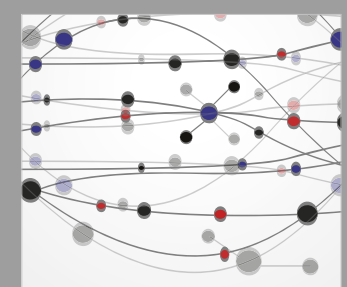

The Scientific World Journal
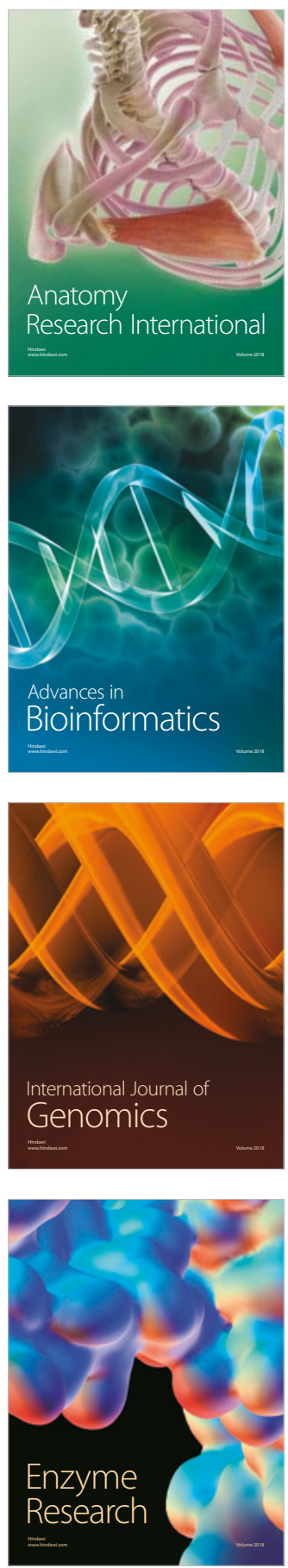
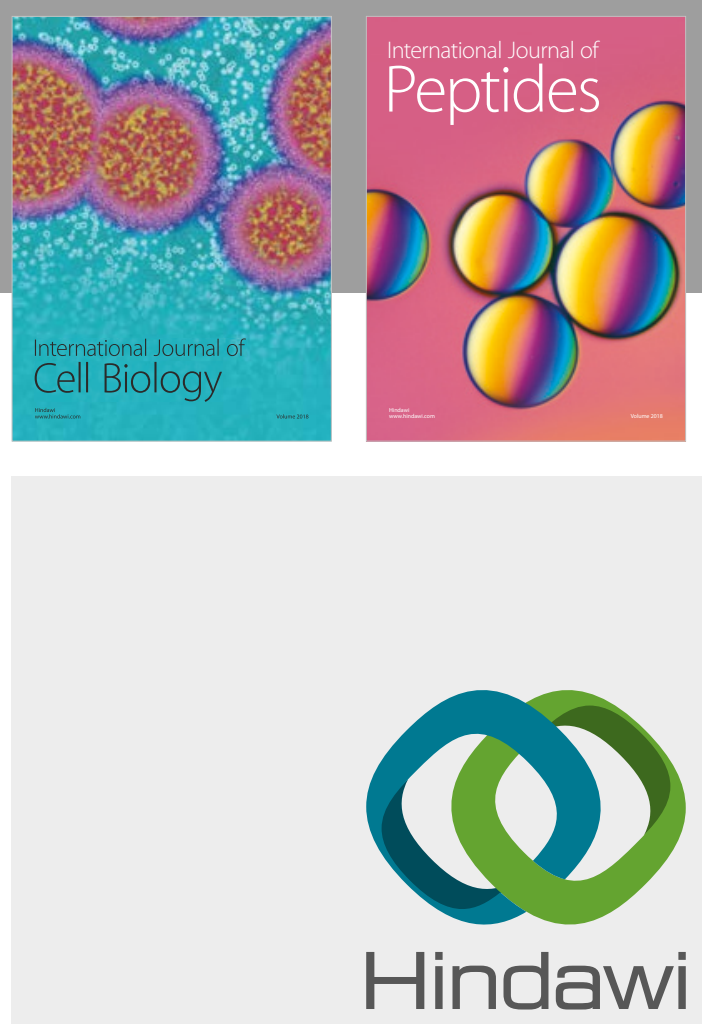

Submit your manuscripts at

www.hindawi.com
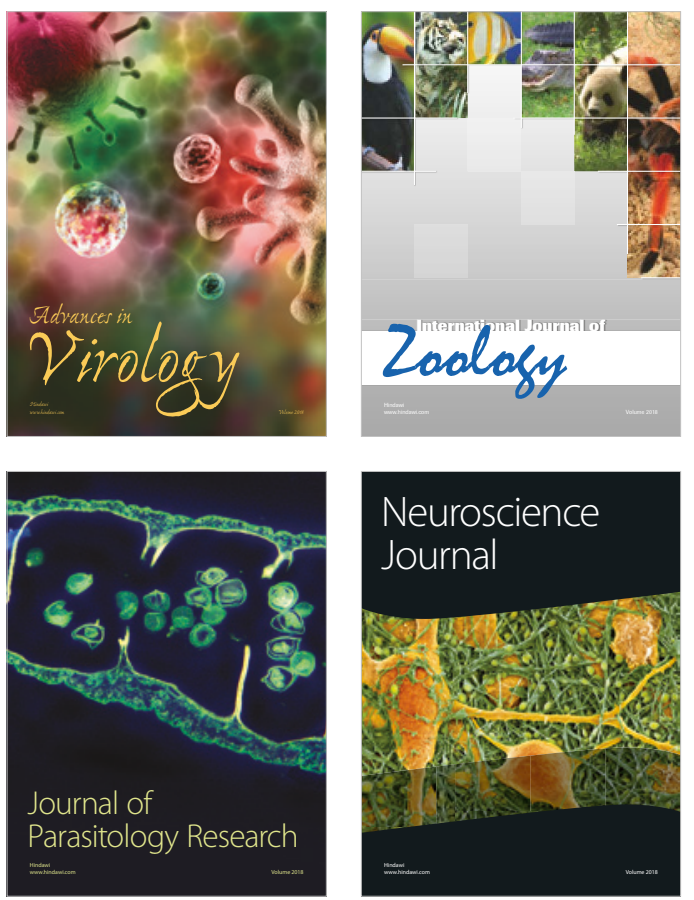
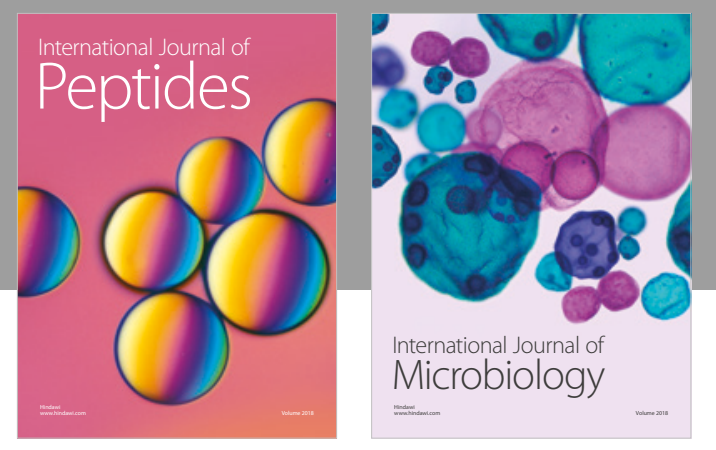

nternational Journal of Microbiology
Journal of
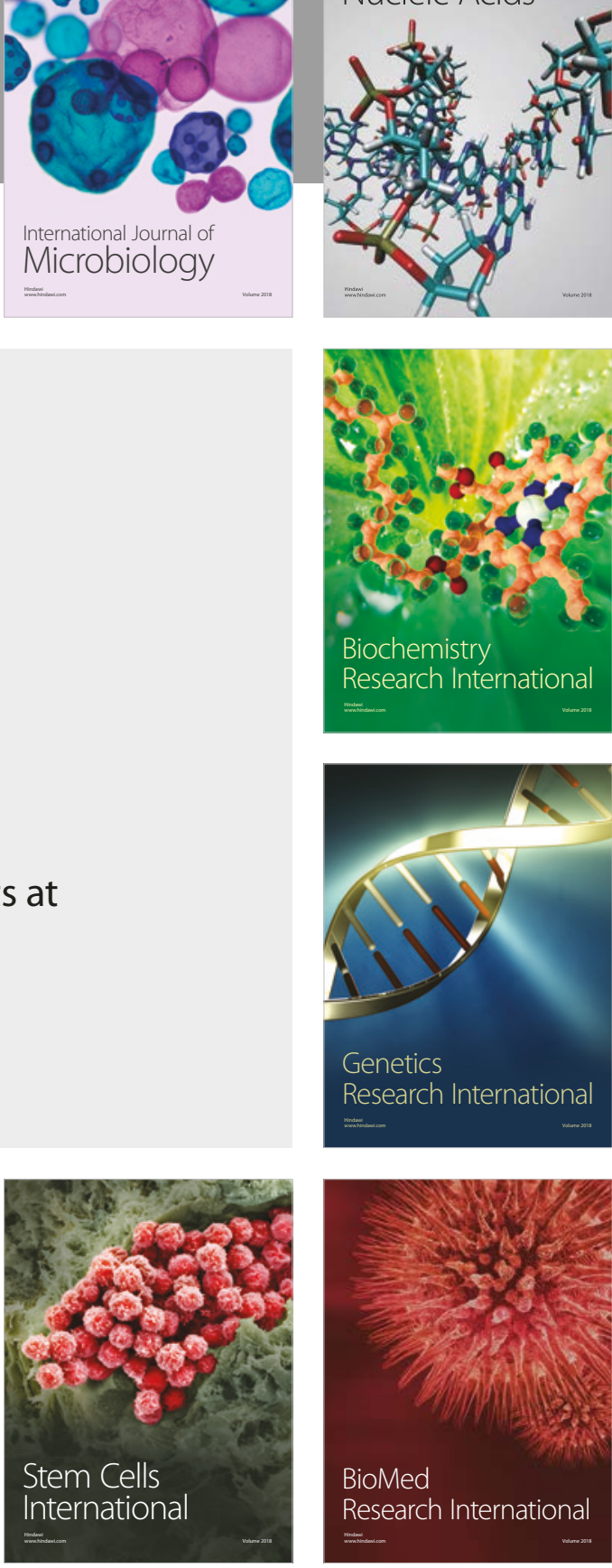
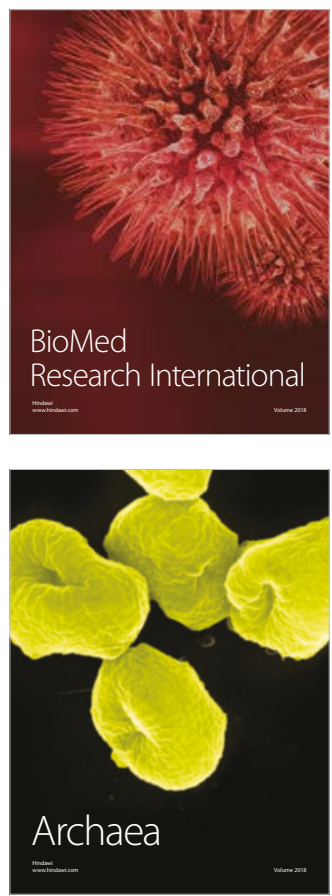